\title{
Surface Micromachining via Solid Electrochemical Reaction on Oxide Ion Conductors
}

\author{
Kai Kamada ${ }^{\mathrm{a}, *}$, Shodai Hirata ${ }^{\mathrm{b}}$, Naoya Enomoto ${ }^{\mathrm{b}}$, Junichi Hojo ${ }^{\mathrm{b}}$ \\ ${ }^{a}$ Department of Materials Science and Engineering, Faculty of Engineering, \\ Nagasaki University, Nagasaki 852-8521, Japan \\ ${ }^{\mathrm{b}}$ Department of Applied Chemistry, Faculty of Engineering, \\ Kyushu University, Fukuoka 819-0395, Japan
}

*Corresponding author: kamada@cstf.kyushu-u.ac.jp

\begin{abstract}
We propose a simple and novel route for the surface microstructuring of tough materials (glassy carbon, $\mathrm{SiC}, \mathrm{W}$ and $\mathrm{Mo}$ ) through a solid electrochemical reaction at a microcontact between the oxide ion conductor and target substrate. More specifically, the surface of materials was locally oxidized by an anodic electrochemical reaction with the oxide ion conductor via the microcontact under a dc bias. Since the oxidation products of the targets were gaseous or sublimable, a fine-patterned surface was obtained as a result of the continuous consumption of the oxidation products formed at the microcontact. The success of the proposed method may stimulate such conventional applications of oxide ion conductors.
\end{abstract}

Keywords: Oxide ion conductor, Microcontact, Micromachining, Solid electrochemical reaction 


\section{Introduction}

The surface microstructuring of a substrate plays a significant role in various technologies such as microelectronics [1] and optoelectronics [2]. The textured surfaces are fabricated using one of two general approaches. One is the topographic deposition of the desired materials on a surface [3]. This is the "build-up" type approach, in which the surface is constructed from a molecular or atomic scale. Micromachining belongs to the other category and can be considered to be a "shaving off' type texturing method. In this communication, we propose a simple and novel route for the surface microstructuring of tough materials through a solid electrochemical reaction at a microcontact between the oxide ion conductor and target substrate. More specifically, the surface of materials is locally oxidized by an anodic electrochemical reaction with the oxide ion conductor via the microcontact under a dc bias. Supposing that the oxidation products are gaseous or sublimable, a fine-patterned surface would be obtained as a result of the continuous consumption of the oxidation products formed around the microcontact. Traditional machining of hard metals and ceramics has been undertaken by mechanical or physical approaches such as electrical discharge machining [4-6], irradiation by focused ion beam [7], and laser ablation [8], which require a high cost. In contrast, since the proposed method corresponds to one of the electrochemical micromachining techniques, no surface distortion and/or stress is induced in the machined workpiece and the machining dimensions (size, depth, shape) can be easily controlled by the area and shape of the microcontact or other 
electrochemical parameters. The following sections will focus on determining out the advantages of the present technique. The success of the proposed method may revolutionize such conventional applications of oxide ion conductors.

Electrochemical reactors utilizing oxide ion conductors are widely employed as fuel cells, chemical sensors, oxygen pumps, and so on. All devices operate by either harvesting an electromotive force equivalent to the difference in the oxygen chemical potential on both sides of the ion conducting separator or transporting oxide ions from one side to the other under an applied dc electric field. On the other hand, electrochemical reactors have also been used in order to purify environmental pollutants, i.e., reductive decomposition of $\mathrm{NO}_{\mathrm{x}}$ or oxidative combustion of particulate carbon particles [9]. Recently, oxide ion conductors have been studied as a source of oxygen negative ions that are generated by application of a high voltage to the conductor in a vacuum [10-12].

Our group has recently proposed a simple solid state technique for the electrochemical micromachining of metal substrates using a metal ion conductor [13-15]. In this method, the metal substrate is locally oxidized and then incorporated into the ion conductor in the form of metal ions via the microcontact between the metal substrate and ion conductor. The substrate is micromachined as a result of the continuous application of an electric field. In a similar manner, the solid electrochemical micromachining of materials producing volatile substances by oxidation would be 
achieved using an oxide ion conductor. Such a novel application extends the possibilities of oxide ion conductors. It seems that hard materials such as carbon based ceramics (glassy carbon and $\mathrm{SiC}$ ) or hard metals (W, Mo) are appropriate targets for the proposed technique, because these non-oxide materials form gaseous or volatile oxidation products. Typically, the microstructures of these materials can be used as microelectrodes or micro-parts for high temperature use [6,16]. Figure 1 depicts a schematic model of the electrochemical system of the proposed solid state micromachining. The solid electrochemical cell consists of cathode | pyramid-like oxide ion conducting ceramics | target $\mid$ anode system. Application of a dc bias to the cell induces the anodic electrochemical reaction of oxide ions $\left(\mathrm{O}^{2-}\right)$ at the microcontact between the conductor and the target. When the target forms volatile or gaseous products as a result of the reaction with $\mathrm{O}^{2-}$ or $\mathrm{O}_{2}$ gas, it is expect that the target is gradually consumed during the electrolysis. In addition, localization of the reaction area, i.e., use of a microcontact, results in position selective etching of the target, then the solid electrochemical micromachining is realized. Conventionally, chemical approaches such as wet (and electrochemical) etching in solutions have been frequently applied by many groups [16,17]. However, a liquid electrolyte is required as a medium, and high-resolution patterning requires masking. While the latter problem is solved by the combined use of position selective laser and ion beam irradiation to draw a minute pattern [18-20] or the application of an ultrashort voltage pulse [21-23]. In the present technique, on the other hand, since the oxide ions can react only at the solid-solid microcontact, the 
machined target can be directly patterned in almost any configuration using an ion conductor with the desired shape.

\section{Experimental}

Solid electrochemical micromachining using an oxide ion conductor was carried out using the electrochemical system shown in Fig. $1.8 \mathrm{~mol} \% \mathrm{Y}_{2} \mathrm{O}_{3}$ doped $\mathrm{ZrO}_{2}$ (yttria stabilized zirconia: YSZ) was employed as the oxide ion conductor. The ceramic or pure metal plates of glassy carbon (GC), $\beta$-SiC, $\mathrm{W}$, and Mo were used as workpieces for the solid electrochemical micromachining after mirror finishing using alumina or diamond fine powder. To suppress oxidation of the entire target in air, application of an electrical bias was performed in an inert $\mathrm{N}_{2}$ atmosphere $\left(p_{\mathrm{O} 2} \sim 0.1 \mathrm{~Pa}\right)$ or in a vacuum (total pressure $\sim 10^{-3} \mathrm{~Pa}$ ) at $900 \sim 1150{ }^{\circ} \mathrm{C}$. Under the present conditions, however, there is no oxygen source for the YSZ in the atmosphere. In order to overcome the problem, the YSZ was mixed with nickel oxide $(\mathrm{NiO})$ which plays the role as an oxygen source to vacancies in the YSZ. For preparation of the composite ceramics of $\mathrm{NiO}$ and YSZ, various amounts of Ni metal particles $(0,1,3,5$, and $10 \mathrm{wt} \%)$ were ultrasonically dispersed in the ethanol slurry of the YSZ powder. After drying the mixed powder, a cylindrical pellet of NiO-YSZ was obtained by uniaxial and subsequent cold isostatic pressing, followed by sintering at $1400{ }^{\circ} \mathrm{C}$ for $5 \mathrm{~h}$ in air. The relative density of the sintered body was measured by Archimedes method. The crystal structure and 
microstructure were investigated using XRD, SEM, and EDS. The ion conducting characteristics of the NiO-YSZ were evaluated by the AC impedance method $(10 \sim 1 \mathrm{MHz})$. The NiO-8YSZ ceramics was polished with emery paper to form a pyramidal ion conductor as shown in Fig. 1. The initial contact diameter was estimated to be about $10 \mu \mathrm{m}$; this value varied slightly with the apex configuration of the hand-polished pyramid and the type of target. A Pt plate attached to the bottom of the NiO-YSZ pyramid was used as the cathode. The solid electrochemical micromachining was carried out by applying a constant current or voltage to the cell using a dc power supply at high temperature under an inert atmosphere as already described. Following the micromachining, the surfaces of the targets were observed by SEM. To better characterize the surface morphology, all SEM samples were held at a $20-60^{\circ}$ angle with respect to the perpendicular electron beam axis. Dimensions of the surface profiles in the target were determined using with a 3D profile measurement unit.

\section{Results and Discussion}

\subsection{Characterization of NiO-YSZ Ceramics}

Table 1 shows the chemical and physical characteristics of the YSZ ceramics with the different $\mathrm{NiO}$ contents. The quantitative analysis revealed that the actual $\mathrm{NiO}$ contents in the composite ceramics were slightly lower than those in the initial mixed powders, indicating 
evaporation of the Ni species during the sintering at $1400{ }^{\circ} \mathrm{C}$. It should be noted that the colors of the NiO-YSZ were dramatically changed with the $\mathrm{NiO}$ content. In contrast to the light brown appearance of $1 \mathrm{wt} \% \mathrm{NiO}$, the samples containing $\mathrm{NiO} \geq 3 \mathrm{wt} \%$ were colored green which corresponded to the native tint of nickel (II) oxide [24]. Figure 2a depicts the XRD patterns of the YSZ ceramics with different amounts of NiO. The presence of intense diffraction lines attributed to the cubic fluorite structure of zirconia appeared in all the patterns. In addition, it was also confirmed the co-existence of $\mathrm{NiO}$ crystal having rock salt type structure above $3 \mathrm{wt} \%$, suggesting that the added Ni metal was completely oxidized to $\mathrm{NiO}$ during the sintering. Kuzjukevics et al. claimed that the solubility limit of $\mathrm{NiO}$ in $8 \mathrm{~mol} \% \mathrm{Y}_{2} \mathrm{O}_{3}$ doped $\mathrm{ZrO}_{2}$ is about $1.5 \mathrm{wt} \%$ [25]. In fact, there is no diffraction line of $\mathrm{NiO}$ in the pattern of the sample including $1 \mathrm{wt} \%$, indicating that all the $\mathrm{Ni}$ atoms dissolve into the lattice, although no shift in the diffraction lines was observed within the experimental error. In the cases over $3 \mathrm{wt} \%$, the crystalline $\mathrm{NiO}$ exceeded the solubility limit present in the grain boundary regions along with a little distribution inside the grains.

\subsection{Electrical Properties of NiO-YSZ Ceramics}

AC impedance measurements of the NiO-YSZ composite ceramics were undertaken in order to study the effect of the $\mathrm{NiO}$ addition on the oxide ion conducting properties. Figure $2 \mathrm{~b}$ shows typical Nyquist plots of the 0 and $3 \mathrm{wt} \% \mathrm{NiO}$ doped YSZ ceramics at $400{ }^{\circ} \mathrm{C}$ in air. In both cases, the arcs at the lower and higher frequencies are due to the resistances of the grain boundary and 
grain bulk, respectively [26]. Since the previous paper [24] suggested 8YSZ containing NiO up to ca. $20 \mathrm{wt} \%$ behaves as a pure ion conductor, the electron conduction in the NiO-YSZ prepared here can be ignored. Figure $2 \mathrm{~b}$ clearly indicates that both resistances in the bulk and grain boundaries were increased by the $\mathrm{NiO}$ addition. The dissolution of $\mathrm{Ni}^{2+}$ into the cubic crystal structure of $8 \mathrm{YSZ}$ might be expected to reduce the bulk conductivity due to defect interactions, because the $8 \mathrm{~mol} \% \mathrm{Y}_{2} \mathrm{O}_{3}$ is an optimized concentration to obtain the maximum conductivity [27]. The increase in the grain boundary resistance is due to the segregation of $\mathrm{NiO}$ [28]. While the addition of $\mathrm{NiO}$ to $8 \mathrm{YSZ}$ produced a negative influence on the conductive properties of the oxide ions, these composites were employed as an oxide ion resource in an inert atmosphere.

\subsection{Solid State Electrochemical Micromachining of Glassy Carbon (GC)}

The solid state electrochemical micromachining of a glassy carbon (GC) plate was performed using a pyramidal YSZ ion conductor with various amount of NiO. As can be expected, the GC will react with oxygen species $\left(\mathrm{O}_{2}, \mathrm{O}^{2-}\right)$ at the microcontact, then local etching will occur as a result of the consumption as $\mathrm{CO}_{2}(\mathrm{~g})$. We investigated the influence of a dc voltage during the potentiostatic electrolysis on the etching possibility of the glassy carbon substrate at $900{ }^{\circ} \mathrm{C}$ for $1 \mathrm{~h}$ using $5 \mathrm{wt} \% \mathrm{NiO}$-doped 8YSZ. Although the application of the lower voltage below $0.5 \mathrm{~V}$ did not cause the etching, the depressions on the GC surface produced by the local reaction were confirmed after the electrolysis above $1 \mathrm{~V}$. Hence, it can be concluded that a dc voltage above ca. $1 \mathrm{~V}$ is 
appropriate to achieve the solid electrochemical micromachining. Figure 3a shows the change in the cell voltage under an applied constant current of $10 \mu \mathrm{A}$ at $900{ }^{\circ} \mathrm{C}$ in $\mathrm{N}_{2}$. The amount of NiO additive significantly affected the overvoltage during the galvanostatic electrolysis. In general, the voltage response in the microelectrode technique depends on the electrical resistance only in the small region near the microcontact, because the current density at the counter electrode (Pt (cathode) $\mid$ NiO-YSZ) would be negligible compared to that at the microcontact $[29,30]$. Taking into account the fact that the ionic conductivity of NiO-YSZ is much lower than the electronic one of the GC, the voltage drop seemed to mainly occur in the NiO-YSZ near the microcontact. In the case of $1 \mathrm{wt} \% \mathrm{NiO}$, the cell voltage was extremely large and unstable during the electrolysis [31,32]. As already stated, $1 \mathrm{wt} \%$ $\mathrm{NiO}$ completely dissolved in the lattice of the YSZ, suggesting that there is no source of oxide ions for the vacancies. The decomposition voltage of zirconia calculated by the Gibbs free energy of formation is about $2.2 \mathrm{~V}$ at $900{ }^{\circ} \mathrm{C}$. Since the voltage significantly exceeded this value, the electrolysis (decomposition) of the YSZ crystal would proceed due to forced transport of the oxide ions. The expectation was supported by the color change of YSZ from green to black during the electrolysis. In contrast, the use of YSZ including more than $3 \mathrm{wt} \% \mathrm{NiO}$ effectively reduced the overvoltage to below $2 \mathrm{~V}$. The $\mathrm{NiO}$ crystals existing in the grain boundary of the YSZ decomposed under a dc bias, and the supplied oxide ions to the vacancies. In fact, the existence of Ni metal was detected in the composite ceramics after electrolysis according to the XRD analysis. Hence, the 
addition of $\mathrm{NiO}$ over $3 \mathrm{wt} \%$ could significantly retard the decomposition of the $\mathrm{YSZ}$ and promote the oxide ion conduction through the cell in the inert atmosphere.

Figure $3 \mathrm{~b}$ displays the surface profile of the GC plate after application of $2 \mathrm{~V}$ for $3 \mathrm{~h}$ using the $5 \mathrm{wt} \% \mathrm{NiO}-\mathrm{YSZ}$ at $900{ }^{\circ} \mathrm{C}$ in $\mathrm{N}_{2}$. The depression seen in the center of the figure indicates the position of the microcontact. The size of the depression on the GC surface after electrolysis was much larger than that formed in the absence of a current flow, suggesting that the mechanical stress induced by the needle-like NiO-YSZ can be ignored. Naturally, the depth was changed by the charge flown. These results indicate that the reaction of the oxide ions with the GC surface via the microcontact successfully led to a local etching (surface micromachining) accompanied by the $\mathrm{CO}_{2}(\mathrm{~g})$ generation. The current efficiencies of the electrochemical micromachining, which were estimated from the machined volume, electric charge, and density of the GC using Faraday's law, were much lower than $100 \%$ (Table 1). The low efficiencies may be caused by the leakage of unreacted $\mathrm{O}_{2}$ gas from the microcontact. The profile also indicates that the GC plate was drilled according to the apex form of the NiO-YSZ, i.e., the inverse pyramid form. However, the dimensions of the micromachining in the GC were expanded as compared with those of the NiO-YSZ apex, suggesting that any leaked $\mathrm{O}_{2}$ gas also corroded the lateral surface of the pyramidal depression. Actually, the cell voltage shown in Fig. 2 was almost constant during the electrolysis, which means that the NiO-YSZ pyramid was always in contact with the GC only at the apex region 
and then the contact area between the NiO-YSZ and GC maintained a constant value. Therefore, use of a smaller flux of oxide ion, i.e., a lower current density, may achieve complete agreement between the shapes of the etched surface and the apex of NiO-YSZ, realizing a manipulation of the aspect ratio of the micromachining.

\subsection{Solid State Electrochemical Micromachining of $\beta$-SiC}

The possibility of the solid state electrochemical micromachining of $\beta$-SiC ceramics was investigated using the identical electrochemical system shown in Fig. 1. As is well-known, oxidation of $\mathrm{SiC}$ proceeds via one of two mechanisms depending on the temperature and partial pressure of oxygen $\left(p_{O 2}\right)[33,34]$. Active oxidation occurs along with evaporation of $\mathrm{SiO}(\mathrm{g})$ at high temperature and low $p_{O 2}$, while passive oxidation forming $\mathrm{SiO}_{2}$ dominates at low temperature and high $p_{O 2}$. If the former oxidation mechanism takes place on the $\beta$-SiC surface using the present technique, the solid electrochemical micromachining of the $\beta$-SiC surface would proceed as a result of loss of $\mathrm{SiO}(\mathrm{g})$ and $\mathrm{CO}(\mathrm{g})$. Figure 4a shows an SEM image of the $\beta$-SiC surface after potentiostatic electrolysis of $5 \mathrm{~V}$ at $1150{ }^{\circ} \mathrm{C}$. Since no detectable change (oxidation or depression) was observed in the surface of the $\beta$-SiC after annealing at an equivalent temperature with no current flow, the depression was fabricated by the solid electrochemical micromachining. The numerous tiny pores with a few $\mu \mathrm{m}$ diameter were discernible in the magnified image (inset in Fig. 4a). The porous surface is one of the characteristics of active oxidation and seems to be produced by evaporation of the gaseous $\mathrm{SiO}$ and 
$\mathrm{CO}$ [35]. Figure 4a also reveals that a dense hump (white region) surrounded the depression. The dense layers could be completely removed by $\mathrm{HF}_{\mathrm{aq}}$ treatment as shown in Fig. $4 \mathrm{c}$, indicating that these regions consists of $\mathrm{SiO}_{2}(\mathrm{~s})$, which grew according to a passive oxidation mechanism induced by the reaction with leaked oxygen gas from the microcontact. The observed current under the applied constant voltage rapidly decreased during the initial stage of electrolysis due to the formation of an insulating $\mathrm{SiO}_{2}$ layer. It also led to lower current efficiencies below $10 \%$. According to the thermodynamic estimation, the passive oxidation of $\mathrm{SiC}$ is more probable than the active oxidation under the present experimental conditions $\left(1150{ }^{\circ} \mathrm{C}, p_{\mathrm{O} 2}=0.1 \mathrm{~Pa}\right)$. Furthermore, the electrochemical $\mathrm{O}_{2}$ evolution at the NiO-YSZ $\mid \mathrm{SiC}$ interface increases the $p_{O 2}$ near the microcontact. However, the electrochemical micromachining, i.e., active oxidation, could interestingly proceed as shown in Fig. 4a. The possible reason is the direct reaction of $\mathrm{SiC}$ with oxide ions at the microcontact. The diffusion of $\mathrm{O}^{2-}$ through thin a $\mathrm{SiO}_{2}$ layer on the $\mathrm{SiC}$ surface under a dc bias and subsequent reaction may also play an important role in the active oxidation. We have also demonstrated that the present method can produce various shapes in the machined surface by controlling the shape and size of the NiO-YSZ conductor as shown in Fig. 4c (line pattern). In conclusion, it was demonstrated that the solid electrochemical micromachining employing the NiO-YSZ ion conductors can fabricate microstructured surfaces of $\beta$-SiC ceramics as a result of local active oxidation.

\subsection{Solid State Electrochemical Micromachining of Hard Metals}


$\mathrm{W}$ and Mo are widely used as high temperature mechanical elements, filaments, and ultra-hard cutting tools because of their high melting points, electrical conductivities, and toughness. Conventionally, the machining of these metals has been carried out by electrical discharge machining or laser ablation. However, these methods have some disadvantages: (1) occurrence of structural defects caused by brittleness, and (2) surface distortion by high energy charging. On the other hand, the oxide forms of these metals are easily sublimated at high temperature. Therefore, the surface micromachining of $\mathrm{W}$ and Mo would be possible by local oxidation at high temperature using the present method. Application of the present method may become one solution of the problems. The solid electrochemical micromachining was undertaken using the system shown in Fig. 1 , where a vacuum atmosphere $\left(\sim 10^{-3} \mathrm{~Pa}\right)$ was adopted to promote the evaporation of the oxidation products. The annealing at $900{ }^{\circ} \mathrm{C}$ without electrolysis did not affect the surface chemistry of these metals according to the XRD patterns before and after the treatment. In contrast, the lower valence oxides $\left(\mathrm{MoO}_{2}, \mathrm{WO}_{2}\right)$ were detected after electrolysis at $1 \mathrm{~V}$ for $1 \mathrm{~h}$ at $900{ }^{\circ} \mathrm{C}$. Figure 5 shows the SEM images and the surface profile of the Mo substrate after the micromachining. The Mo surface was drilled in the form of an inverse-pyramid similar to the cases for the $\mathrm{GC}$ and $\mathrm{SiC}$, in which the micromachining of the $\mathrm{W}$ plate was also feasible. As a matter of fact, no depression was produced in the absence of the electric field. These results point out that the local area of the Mo substrate was selectively scratched as a result of the oxidation with $\mathrm{O}^{2-}$ and/or $\mathrm{O}_{2}$ that originated from the 
NiO-YSZ, and subsequent sublimation of the oxides. In the case of $\mathrm{SiC}$, the application of $1 \mathrm{~V}$ did not induce etching (i.e., negligible current flow) even at higher temperature $\left(1150{ }^{\circ} \mathrm{C}\right)$ due to the voltage drop at the electrically insulating $\mathrm{SiO}_{2}$ layer covering the $\mathrm{SiC}$ surface. In contrast, the surface oxides produced on the Mo and $\mathrm{W}$ are highly conductive, therefore, they do not disturb the ion migration through the electrochemical cell. Accordingly, the micromachining of these metals effectively proceeded (current efficiency: 50 and $85 \%$ for Mo and W, respectively). The higher efficiency for the Mo substrate is due to the lower sublimation temperature of Mo oxide. In summary, the electrochemical micromachining of ultra-hard metals (Mo and W), which are difficult to control the surface microstructure, was achieved using the proposed technique.

\section{Conclusions}

Solid electrochemical reactions at microcontact have widely used in the field of solid state ionics, which deals with fast ion conduction in solids [36]. Especially, the microcontact plays an important role in the measurement of local conductivity in ceramic material [37] and transference numbers in mixed electronic-ionic conductors $[29,30]$. By contrast, we have proposed new applications of ion conductor with micro-interface, for instance, an ion transport at the microcontact has been applied to a pinpoint doping into the solid materials [38,39]. In this study, it was demonstrated that a selective oxidation of the non oxide plates by the oxide ion conductor realizes 
the local consumption i.e., surface etching. In each case, such achievements were mainly caused by formation of gaseous or volatile products. Various materials generating the gas products such as nitride and alloy steels may be possible as other targets. The proposed application of the oxide ion conductor has many advantages over the conventional electrochemical method. For example, no solutions are required, and the substrate can be directly patterned in other merits commonly noted with respect to the traditional one: easy control of machining size and three dimensional microstructure by electrochemical parameters and contact configuration. On the other hand, the present technique has some disadvantages such as the relative coarse machining accuracy, the slow etching rate, the roughness of the machined surface, and requirement of high temperature or vacuum conditions. In addition, high temperature operation is required for attaining a high ionic conductivity of solid electrolyte, and reaction products cannot be completely removed from the system during the electrolysis. Therefore, in the future, these problems will be solved by advances in microcontact fabrication, optimization of electrolysis conditions, and use of oxide ion conductor driving even at lower temperature. 


\section{References}

[1] Y.S.S. Wan, J.L.H. Chau, A. Gavriilidis, K.L. Yeung, Microporous Mesoporous Mater. 42 (2001) 157.

[2] D. Xu, L. Wang, G.F. Ding, Y. Zhou, A.B. Yu, B.H. Cai, Sens. Actuators A 93 (2001) 87.

[3] B. Tan, K. Venkatakrishnan, K.G. Tok, Appl. Surf. Sci. 207 (2003) 365.

[4] Y.C. Lin, L.R. Hwang, C.H. Cheng, P.L. Su, J. Mater. Processing Tech. 206 (2008) 491.

[5] H. Nakaoku, T. Masuzawa, M. Fujino, J. Mater. Processing Tech. 187-188 (2007) 274.

[6] G. Cao, W. Zhao, Z. Wang, Y. Guo, J. Mater. Processing Tech. 168 (2005) 83.

[7] D.Z. Xie, B.K.A. Ngoi, Y.Q. Fu, A.S. Ong, B.H. Lim, Appl. Surf. Sci. 225 (2004) 54

[8] J.P. Desbiens, B.K.A. Ngoi, Y.Q. Fu, A.S. Ong, B.H. Lim, Sens. Actuators A 136 (2007) 554.

[9] K. Hamamoto, Y. Fujishiro, M. Awano, Solid State Ionics 177 (2006) 2297.

[10] Y. Torimoto, A. Harano, T. Suda, M. Sadakata, Jpn. J. Appl. Phys. 36 (1997) L238.

[11] Y. Fujiwara, A. Kaimai, J.-O. Hong, K. Yashiro, Y. Nigara, T. Kawada, J. Mizusaki, J. Electrochem. Soc. 150 (2003) E117.

[12] T. Sakai, Y. Fujiwara, A. Kaimai, K. Yashiro, H. Matsumoto, Y. Nigara, T. Kawada, J. Mizusaki, Solid State Ionics 408-412 (2006) 1127.

[13] K. Kamada, M. Tokutomi, M. Inada, N. Enomoto, J. Hojo, J. Ceram. Soc. Jpn. 115 (2007) 672.

[14] K. Kamada, M. Tokutomi, N. Enomoto, J. Hojo, Electrochim. Acta 52 (2007) 3739.

[15] K. Kamada, K. Izawa, Y. Tsutsumi, S. Yamashita, N. Enomoto, J. Hojo, Y. Matsumoto, Chem. Mater. 17 (2005) 1930, Correction 18 (2006) 1713.

[16] O.L. Guise, J.W. Ahner, M.C. Jung, P.C. Goughnour, J.T. Yates, Jr., Nano Lett. 2 (2002) 191.

[17] W.S. Chang, Sensors Actuators A 112 (2004) 36.

[18] P.F. Chauvy, P. Hoffmann, D. Landolt, Electrochem. Solid-State Lett. 4 (2001) C31.

[19] P.F. Chauvy, P. Hoffmann, D. Landolt, Appl. Surf. Sci. 211 (2004) 113.

[20] E.J. Teo, M.B.H. Breese, E.P. Tavernier, A.A. Bettiol, F. Watt, M.H. Liu, D.J. Blackwood, Appl. Phys. Lett. 84 (2004) 3202.

[21] R. Schuster, V. Kirchner, P. Allongue, G. Ertl, Science 289 (2000) 98.

[22] P. Allongue, P. Jiang, V. Kirchner, A.L. Trimmer, R. Schuster, R. J. Phys. Chem. B 108 (2004) 14434.

[23] V. Kirchner, X. Xia, R. Schuster, Acc. Chem. Res. 34 (2001) 371.

[24] S. Linderoth, N. Bonanos, K.V. Jensen, J.B. Bilde-Sorensen, J. Am. Ceram. Soc. 84 (2001) 2652 .

[25] A. Kuzjukevics, S. Linderoth, Solid State Ionics 93 (1997) 255. 
[26] J.V. Herle, R. Vasquez, J. Eur. Ceram. Soc. 24 (2004) 1177.

[27] V. Esposito, D.Z. de Florio, F.C. Fonseca, E.N.S. Muccillo, R. Muccillo, E. Traversa, J. Eur. Ceram. Soc. 25 (2005) 2637.

[28] M. El-sayed Ali, O.A. Abdelal, A.A. Hassan, Solid State Ionics 178 (2007) 1463.

[29] H.D. Wiemhöfer, Ber. Bunsen-Ges. Phys. Chem. 97 (1993) 461.

[30] W. Zipprich, S. Waschilewski, F. Rocholl, H.D. Wiemhöfer, Solid State Ionics 101-103 (1997) 1015.

[31] J. Janek, S. Majoni, Ber. Bunsenges. Phys. Chem. 99 (1995) 14.

[32] J. Janek, Solid State Ionics 131 (2002) 129.

[33] J. Eck, M. Balat-Pichelin, L. Charpentier, E. Bêche, F. Audubert, J. Eur. Ceram. Soc. 28 (2008) 2995.

[34] B. Schneider, A. Guette, R. Naslain, M. Cataldi, A. Costecalde, J. Mater. Sci. 33 (1998) 535.

[35] T. Goto, J. Ceram. Soc. Jpn. 110 (2002) 884.

[36] J. Fleig, Solid State Ionics 161 (2002) 279.

[37] J. Fleig, J. Maier, Phys. Chem. Chem. Phys. 1 (1999) 3315.

[38] K. Kamada, S. Udo, Y. Matsumoto, Solid State Ionics 146 (2002) 387.

[39] K. Kamada, S. Yamashita, Y. Matsumoto, J. Mater. Chem. 13 (2003) 1265.

\section{Figure $s$}

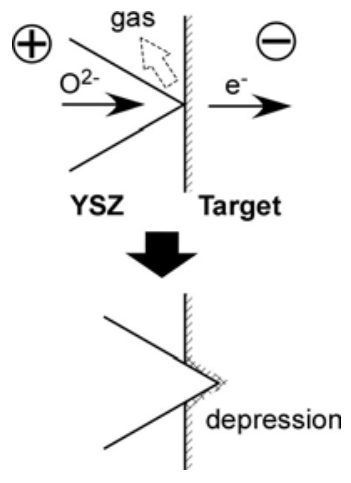

Figure 1: Schematic model for electrochemical micromachining of hard materials (e.g. SiC) using an oxide ion conductor. 

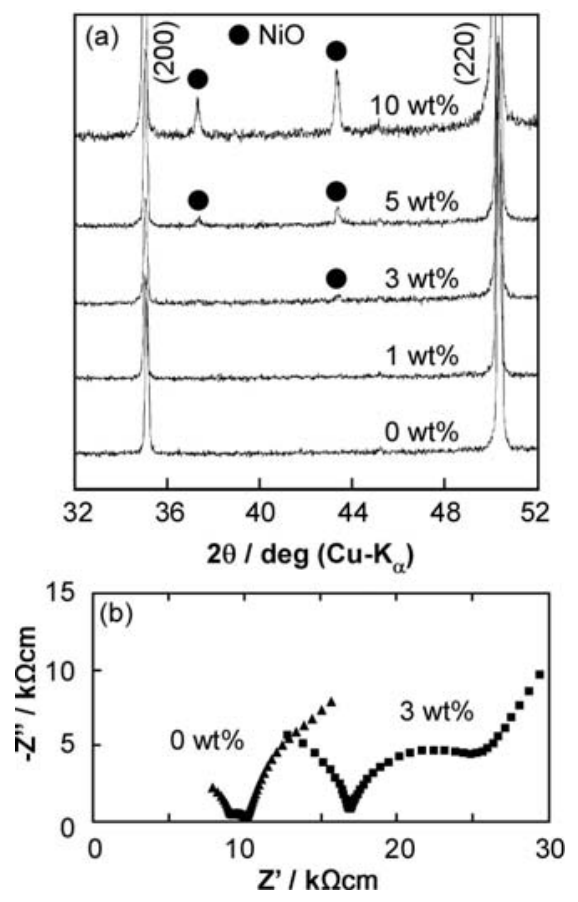

Figure 2: (a) XRD patterns of the YSZ ceramics including different amounts of $\mathrm{NiO}$, and (b) Nyquist plots of 0 and $3 \mathrm{wt} \% \mathrm{NiO}$ doped YSZ ceramics at $400{ }^{\circ} \mathrm{C}$.
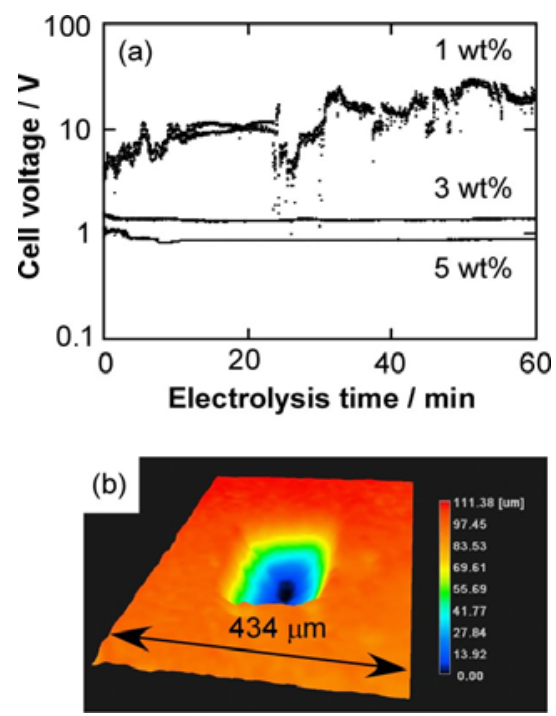

Figure 3: (a) Typical time evolution of cell voltage under a constant current electrolysis $(10 \mu \mathrm{A})$ using the glassy carbon plate at $900{ }^{\circ} \mathrm{C}$. (b) Surface profile of the GC plate after a $3 \mathrm{~h}$ electrolysis using $5 \mathrm{wt} \% \mathrm{NiO}-\mathrm{YSZ}$. 

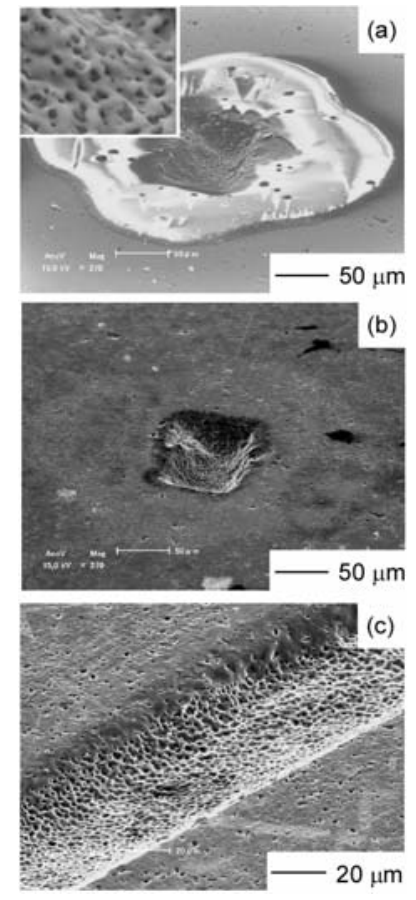

Figure 4: SEM images of surface depression of $\beta$-SiC plate after applying $5 \mathrm{~V}$ for $5 \mathrm{~h}$ at $1150{ }^{\circ} \mathrm{C}$ (a), and subsequent $\mathrm{HF}_{\mathrm{aq}}$ treatment. (b) Line-patterned $\beta$-SiC surface after applying $10 \mathrm{~V}$ for $5 \mathrm{~h}$ at $1150{ }^{\circ} \mathrm{C}$.
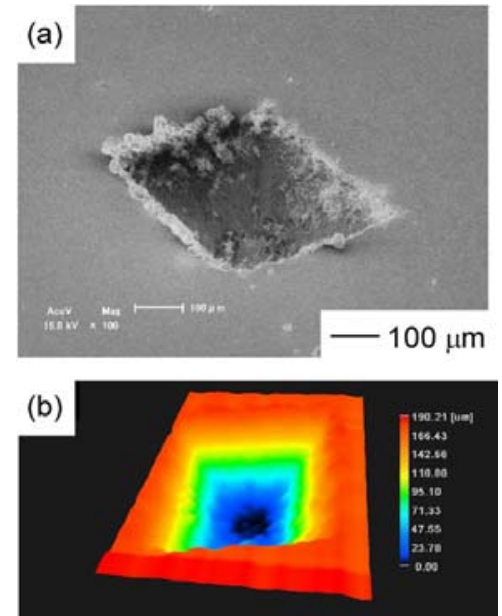

Figure 5: SEM image (a) and surface profile (b) of Mo surface after micromachining at $1 \mathrm{~V}$ for $1 \mathrm{~h}$ at $900{ }^{\circ} \mathrm{C}$. 
Table 1

Composition, relative density and electrical conductivity of NiO-YSZ composite ceramics.

\begin{tabular}{|c|c|c|c|c|}
\hline $\begin{array}{c}\text { NiO in raw powder } \\
\left(\mathrm{wt}^{\mathrm{a}}\right)^{\mathrm{a}}\end{array}$ & $\begin{array}{c}\mathrm{NiO} \text { in ceramics } \\
(\mathrm{wt} \%)\end{array}$ & $\begin{array}{c}\text { Relative } \\
\text { density (\%) }\end{array}$ & Appearance & $\begin{array}{c}\text { Current efficiency } \\
(\%)^{\mathrm{b}}\end{array}$ \\
\hline 1 & 0.49 & 96.0 & light brown & 16 \\
\hline 3 & 2.40 & 93.1 & green & 20 \\
\hline 5 & 4.68 & 93.6 & green & 33 \\
\hline 10 & 9.49 & 97.4 & green & 13 \\
\hline
\end{tabular}

${ }^{a}$ In actual, Ni metal nanoparticle was added as a Ni source.

${ }^{\mathrm{b}}$ Electrochemical micromachining of the glassy carbon plate at $10 \mu \mathrm{A}$ and $900{ }^{\circ} \mathrm{C}$ for $3 \mathrm{~h}$. 